THU0271

EMERGENCE OF SEVERE SPONDYLOARTHROPATHY RELATED ENTHESEAL PATHOLOGY FOLLOWING VEDOLIZUMAB THERAPY FOR INFLAMMATORY BOWEL DISEASE

S. Dubash ${ }^{1,2}$, T. Marianayagam ${ }^{3}$, T. Al-Araimi ${ }^{4}$, C. Pagnoux ${ }^{4}$, A. Weizman ${ }^{4}$, M.- $^{-}$ L. Tran Minh ${ }^{5}$, M. Allez ${ }^{5}$, P. Richette ${ }^{5}$, H. Marzo-Ortega ${ }^{1,2}$, D. McGonagle ${ }^{1,2} .{ }^{1} \mathrm{NIHR}$ Leeds Biomedical Research Centre, Leeds Teaching Hospitals, ${ }^{2}$ Leeds Institute of Rheumatic and Musculoskeletal Medicine, University of Leeds, Leeds; ${ }^{3}$ Rheumatology, East and North Hertfordshire NHS Trust, Stevenage, UK; ${ }^{4}$ Division of Rheumatology, Mount Sinai Hospital, Toronto, Canada; ${ }^{5}$ Hopital Lariboisiere, University Hospitals Group, Paris, France

Background: The Spondyloarthritides $(\mathrm{SpA})$ and inflammatory bowel disease (IBD) share common aetiopathogenetic and clinical manifestations. Vedolizumab, a humanised IgG1 monoclonal antibody to $\alpha 4 \beta 7$ integrin, has been approved for the treatment of inflammatory bowel disease (IBD) and inhibits $\alpha 4 \beta 7$ integrin at the gut level. Vedolizumab therapy for IBD has been associated with mild SpA related features including sacroilitis and synovitis. Herein, we report the emergence of severe SpA under therapy with Vedolizumab.

Objectives: We conducted a clinical evaluation of 7 vedolizumab treated patients with IBD that developed severe active SpA and/or enthesopathy with the aim of characterising the vedolizumab associated SpA/entheseal flares.

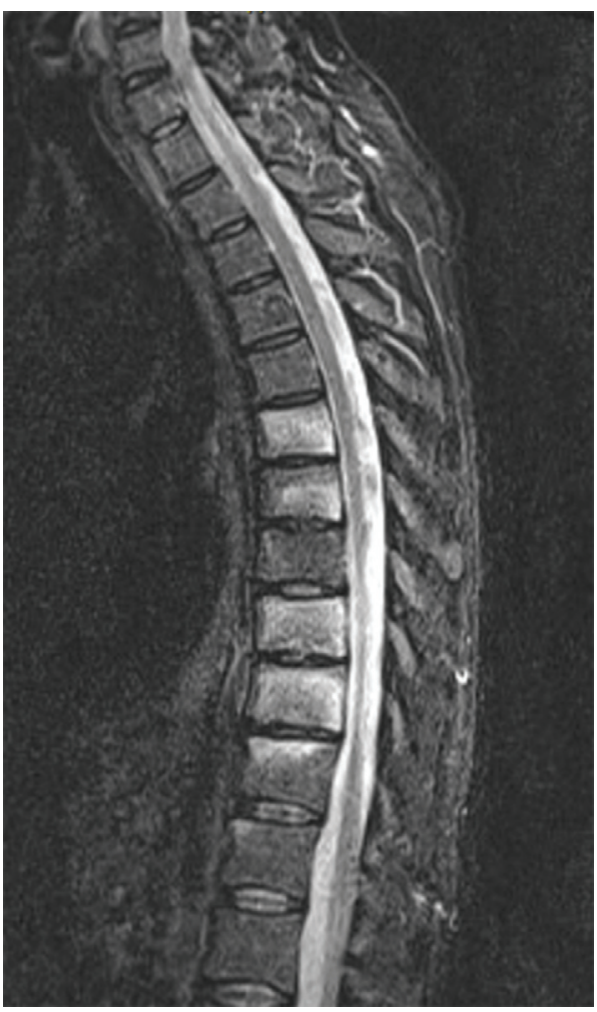

Methods: Vedolizumab treated IBD patients with SpA/enthesopathy were identified across four hospitals. We identified clinical, biochemical and imaging characteristics within routine case records as part of a clinical evaluation.
Results: We identified 6/7 subjects that developed de novo SpA/enthesopathy and 1/7 (subject 1 ) with a severe flare of pre-existing $\mathrm{SpA}$. There were $3 / 7$ patients hospitalised due to the severity of skeletal disease. The median time from vedolizumab initiation to flare was 10 weeks (table 1 below). Subject 4 developed newonset SpA with severe spinal vertebral end-plate oedema (T6-12) and inflammatory Romanus lesions (L3-4) (image below). Acute sacroiliitis was identified on $\mathrm{MRI}$ in 3 subjects, one of which showed evidence of radiographic bilateral grade 2 sacroiliitis. In at least 4 cases the IBD disease activity was considered to be low or well controlled. Following vedolizumab discontinuation, so far 3 patients have switched to alternative biologic therapies including certolizumab pegol, golimumab, and 1 subject to sulphasalazine.

$\mathrm{cpd}=$ cigarettes per day, $\mathrm{MTX}=$ methotrexate, $\mathrm{AZA}=$ azathioprine, $\mathrm{OC}=$ oral cortico steroid, Pred=prednisolone, $\mathrm{nr}=$ non radiographic, $\mathrm{MRI}+\mathrm{ve}=\mathrm{MRI}$ positive, $\mathrm{XR}+\mathrm{ve}=$ radiograph positive, $\mathrm{NA}=$ not available

Conclusions: This case series demonstrates severe vedolizumab associated $\mathrm{SpA} /$ enthesopathy that resulted in hospitalised cases. The severity of vedolizu mab related SpA flares is relatively severe disease in comparison to the literature. We recognise that vedolizumab is efficacious in IBD, however our observations highlight the need to monitor symptoms to identify patients that develop axial or peripheral SpA several weeks from commencing vedolizumab.

Disclosure of Interest: None declared

DOI: 10.1136/annrheumdis-2018-eular.5649

\section{THU0272 1 WHICH SCORING METHOD DEPICTS SPINAL RADIOGRAPHIC DAMAGE IN (EARLY) AXIAL SPONDYLOARTHRITIS BEST? FIVE-YEAR RESULTS FROM THE DESIR COHORT}

S. Ramiro $^{1}$, P. Claudepièrre ${ }^{2}$, A. Sepriano ${ }^{1}$, M. van Lunteren ${ }^{1}$, A. Molto $^{3}$, A. Feydy ${ }^{3}$, M.A. D' Agostino ${ }^{4}$, D. Loeuille ${ }^{5}$, M. Dougados ${ }^{3}$, M. Reijnierse ${ }^{1}$, D. van der Heijde ${ }^{1} .{ }^{1}$ Leiden University Medical Center, Leiden, Netherlands; ${ }^{2}$ Université Paris Est Créteil, Créteil; ${ }^{3}$ Paris Descartes University; ${ }^{4}$ Université Versailles-Saint Quentin en Yvelines Boulogne-Billancour, Paris; ${ }^{5}$ University of Nancy, Nancy, France

Background: Scores capturing spinal radiographic damage have been proposed and compared in r-axSpA. In early phases of the disease, it is still unknown how these perform.

Objectives: To compare the performance of different radiographic scores of the spine in patients with early axial spondyloarthritis (axSpA).

Methods: Five-year follow-up data (baseline, 2 and 5 years) from the DESIR cohort, including patients with early axSpA, have been used. Spine (cervical, thoracic and lumbar), sacro-iliac joints (SI), and hips were scored on radiographs centrally and independently by 3 readers (scores averaged) for the calculation of different radiographic methods (table 1). Following the OMERACT filter, scores were compared with regard to truth, discrimination (sensitivity to change and reliability) and feasibility. Baseline status scores, and 2- and 5 year change scores were calculated for each of the methods, as well as the proportion of patients with a net change (number of patients with a positive change minus number of patients with a negative change divided by all patients) above the smallest detectable change (SDC). The proportion of total variance explained by the patient ('true variance') was calculated for the change scores of the different instruments and their components using ANOVA, as a measure of reliability.

Results: In total, 699 patients (mean age 34 (SD 9) years, $47 \%$ males) had at least one radiograph available. Mean baseline and 5 year change scores were: mSASSS 0.4(SD 1.5) and 0.4 (1.8), RASSS 0.5 (1.6) and 0.6 (2.2), SASSS 0.2 (0. 7) and 0.3 (1.1), BASRI spine 1.0 (1.2) and $0.2(0.6)$, BASRI spine with thoracic spine: $1.1(1.4)$ and $0.3(0.7)$, BASRI total $1.0(1.3)$ and $0.3(0.6)$ and BASRI total with thoracic spine $1.2(1.4)$ and $0.3(0.7)$, respectively. SDCs and proportion of 2 and 5 year change, including net change, are presented in the table 1 . The

\begin{tabular}{|c|c|c|c|c|c|c|c|}
\hline Subject number & 1 & 2 & 3 & 4 & 5 & 6 & 7 \\
\hline Age, $M / F$ & $28, M$ & $48, M$ & $33, F$ & $50, M$ & $35, F$ & $40, \mathrm{~F}$ & $21, F$ \\
\hline Hospitalised & $\mathrm{Y}$ & $\mathrm{N}$ & $\mathrm{N}$ & $\mathrm{N}$ & Y & Y & $\mathrm{N}$ \\
\hline $\begin{array}{l}\text { Vedolizumab } \\
\text { exposure (weeks) }\end{array}$ & 14 & 20 & 20 & 6 & 8 & 10 & 5 \\
\hline SpA type & $\begin{array}{l}\text { per+axSpA (MRI+ve, } \\
\text { perifacetal spinal } \\
\text { vertebral oedema) }\end{array}$ & $\begin{array}{c}\text { per+axSpA } \\
\text { (acute sacroiliitis } \\
\text { MRI+ve) }\end{array}$ & $\begin{array}{c}\text { axSpA } \\
\text { (MRI } \\
+ \text { ve sacroiliitis) }\end{array}$ & $\begin{array}{l}\mathrm{nr}-\mathrm{axSpA}(\mathrm{MRI}+\mathrm{ve} \text {, extensive thoracolumar } \\
\text { vertebral oedema/osteitis and inflammatory } \\
\text { corner lesions) }\end{array}$ & $\begin{array}{c}\text { nr- } \\
\text { axSpA }\end{array}$ & $\begin{array}{l}\text { Enthesitis/ } \\
\text { periostitis distal tibio- } \\
\text { fibular (MRI+ve) }\end{array}$ & $\begin{array}{l}\text { per+axSpA (MRI } \\
\quad+\text { ve and XR } \\
\text { +ve sacroliliitis)) }\end{array}$ \\
\hline HLA-B27 & $\mathrm{N}$ & NA & NA & $\mathrm{N}$ & Y & NA & $\mathrm{N}$ \\
\hline Smoker (cpd) & 15 & NA & NA & 25 & $\mathrm{~N}$ & NA & $\mathrm{N}$ \\
\hline EIMs (Uveitis, PsO) & $\mathrm{N}$ & $\mathrm{N}$ & $\mathrm{PsO}$ & $\mathrm{N}$ & $\mathrm{PsO}$ & $\mathrm{N}$ & $\mathrm{N}$ \\
\hline IBD activity & Low & NA & NA & High & Low & Low & Low/well controlled \\
\hline $\mathrm{CRP}$ at flare $(\mathrm{mg} / \mathrm{l})$ & 216 & $<5$ & $<5$ & 24 & 24 & 28 & 55 \\
\hline $\begin{array}{l}\text { Concomitant } \\
\text { immunosuppressive } \\
\text { therapy }\end{array}$ & MTX $15 \mathrm{mg} \mathrm{s} / \mathrm{c} /$ week & AZA $150 \mathrm{mg} /$ day & $\begin{array}{c}\text { OC (Pred } \\
0.5 \mathrm{mg} / \text { day }\end{array}$ & Nil & Nil & OC (4 mg Pred) & Nil \\
\hline
\end{tabular}

